\title{
Impacto del covid-19 en las exportaciones de banano, camarón y flores durante el 2020
}

\section{Impact of covid-19 on banana, shrimp and flower exports during 2020}

DOI: $10.46932 / \mathrm{sfjdv} 2 \mathrm{n} 4-050$

Received in: March 1st, 2021

Accepted in: May 30th, 2021

\section{Pauleth Estefanny Peñaloza Veintimilla}

Estudiante de economía agropecuaria

Universidad Técnica de Machala. Km 5 1/2 vía Pasaje

Machala-Ecuador

E-mail: ppenaloza1@utmachala.edu.ec

\section{Andrea del Cisne Vega Granda}

Economista

Estudiante de la Universidad Técnica de Machala, Machala, Ecuador.

E-mail: avega@utmachala.edu.ec

\section{Víctor Javier Garzón Montealegre}

Economista

Estudiante de la Universidad Técnica de Machala, Machala, Ecuador.

E-mail:vgazon@utmachala.edu.ec

\section{Eveligh Prado-Carpio}

Ingeniera comercial

Magíster en Economía Agraria, Economista, Docente de la Universidad Técnica de Machala, Machala, Ecuador.

Magíster en Economía Agraria, Economista, Docente de la Universidad Técnica de Machala, Machala, Ecuador.

E-mail: eprado@utmachala.edu.ec

\section{Jessica Maribel Quezada Campoverde}

Ingeniera agrónoma

Doctora en Ciencias Agrarias, Magister en Administración de Empresa, Docente de la Universidad

Técnica de Machala, Machala, Ecuador.

Universidad Técnica de Machala

E-mail: jquezada@utmachala.edu.ec

\section{RESUMEN}

Debido a la aparición del nuevo virus llamado covid-19 que se originó en Wuhan-China y que rápidamente se propagó alrededor del mundo, el mismo ocasionó graves problemas en todos los sectores, por lo que los gobiernos decidieron realizar un confinamiento en los primeros meses del 2020, con ello el cierre de los puertos, aeropuertos y fronteras, así como también, la reducción de horas de trabajo, paralización del transporte, entre otros. Las regiones más afectadas por la pandemia fueron América Latina y El Caribe. Los sectores más dinámicos en la economía en Ecuador son: el bananero, camaronero y de las flores, los mismos que en los últimos años han aumentado su contribución al Producto Interno Bruto (PIB). El objetivo del presente artículo es analizar el impacto del covid-19 en las exportaciones de banano, camarón 
y flores tomando en cuenta los factores preponderantes que han hecho que estos sectores se vean afectados durante el periodo 2020. Se realizó mediante un diseño no experimental, descriptivo, para la sección de resultados se tomó la información de páginas oficiales y seguidamente su análisis de los tres sectores. Se concluye que para el 2020, las exportaciones ecuatorianas fueron positivas, debido a que tuvieron un crecimiento en los productos de banano y camarón; mientras que, las flores fue el sector más perjudicado. Los mercados más importantes para las exportaciones del país son EEUU, la Unión Europea y China.

Palabras claves: Covid-19, productos, economía, exportaciones, mercados.

\begin{abstract}
Due to the appearance of the new virus called covid-19 that originated in Wuhan-China and that quickly spread around the world, it caused serious problems in all sectors, so the governments decided to carry out a lockdown in the first months of 2020, with this the closure of ports, airports and borders, as well as the reduction of working hours, paralysis of transport, among others. The regions most affected by the pandemic were Latin America and the Caribbean. The most dynamic sectors in the economy in Ecuador are: the banana, shrimp and flower sectors, the same ones that in recent years have increased their contribution to the Gross Domestic Product (GDP). The objective of this article is to analyze the impact of covid-19 on banana, shrimp and flower exports, taking into account the preponderant factors that have caused these sectors to be affected during the 2020 period. It was carried out using a non-experimental design, descriptive, for the results section the information from official pages was taken and then its analysis of the three sectors. It is concluded that for 2020, Ecuadorian exports were positive, due to the growth in banana and shrimp products; while flowers were the most affected sector. The most important markets for the country's exports are the US, the European Union and China.
\end{abstract}

Keywords: Covid-19, products, economy, exports, markets.

\title{
1 INTRODUCCIÓN
}

En diciembre del 2019, surgió un nuevo virus conocido como coronavirus o denominado también covid-19 (SARS-CoV-2) en Wuhan-China, siendo la OMS (Organización Mundial de la Salud) la entidad que da a conocer la existencia de este virus a nivel mundial (OMS, 2020).

El covid-19 alrededor del mundo se expandió rápidamente por lo que los gobiernos adoptaron medidas y esto conllevó serias dificultades para la economía mundial, asociado a que durante el primer semestre del 2020 las fronteras se cerraron. La mayoría de las actividades de producción se encontraron afectadas por la pandemia, iniciando por Asia, Europa, América del Norte y posteriormente a los demás continentes.

En Ecuador el primer bimestre del 2020 la producción y exportación de productos primarios fue estable, a finales de febrero se detectó el primer caso de covid-19 en el país, considerado hasta ese momento una epidemia, siendo hasta marzo declarado como pandemia por la OMS. Debido a esta situación que vivió el país, para el mes de marzo inició el confinamiento por 60 días en toda la población, lo que originó rápidamente un cambio en la realización de todas las actividades productivas, en el sector agroexportador, es decir, la reducción de las horas de trabajo, la paralización del transporte, el cierre de 
fronteras, aeropuertos, puertos, entre otros. Del mismo modo, también afectó en la dinámica de la economía no solo en el país sino también alrededor del mundo.

En un informe de la CEPAL (Comisión Económica para América Latina y El Caribe) nos explica que los valores de las exportaciones de bienes se redujeron en un $17 \%$ entre los meses de enero a mayo del 2020 en relación al año anterior, debido a que, existió un choque entre oferta (el cierre parcial del aparato productivo) como en la demanda (contracción económica en los principales mercados de la región). Por otro lado, China tuvo una contracción del $2 \%$ que el resto de economía, de tal manera que, a partir del mes de marzo pudo controlar el virus y su economía se activó rápidamente, lo que resultó positivo para las exportaciones de materias primas de los países sudamericanos. Finalmente, las regiones de América Latina y El Caribe fueron las más perjudicadas durante la pandemia (CEPAL, 2020).

El objetivo que se desarrollará en el trabajo investigativo es analizar el impacto del covid-19 en las exportaciones de banano, camarón y flores durante el 2020 con una comparación con el año anterior.

\section{PRODUCCIÓN DE ALGUNOS PRODUCTOS AGRÍCOLAS EN EL MUNDO}

La FAO (Organización de las Naciones Unidas para la Alimentación y la Agricultura) a Ecuador lo cataloga como un país exportador neto ya sea en productos energéticos como agroalimentarios. Esto quiere decir que, el país tiene la capacidad de solventar la producción de productos alimenticios, evitando así la escasez alimentaria y a las distintas necesidades básicas energéticas para su población, del mismo modo, el de exportar a distintos mercados que requieren de nuestros productos para complacer en la oferta doméstica (Lucero, 2020).

El banano es considerado como uno de los principales productos en cuanto en producción y comercio agrícolas mundialmente y en los últimos años se obtuvo como resultado el rápido crecimiento en cuanto a la población de los países productores, de igual forma en la demanda mundial en importaciones y en los volúmenes en comercio y producción (FAO, 2020).

El sector camaronero ecuatoriano a nivel mundial se ubica como el cuarto productor y el primer productor del hemisferio occidental de camarón. Por otro lado, en temas de entradas de divisas por exportaciones al país, este sector se ubica como el segundo rubro detrás del petróleo y para el sector privado representa la mayor fuente de entradas desde el exterior (Jaramillo, Argüello, \& Pacific Advisor, 2020).

Con respecto a la producción en el sector acuícola el $90 \%$ de la oferta surge de China que se posiciona como el mayor productor; en cambio, en América está Brasil, Colombia, Ecuador y México son los principales países productores de camarón (Beltrán, 2017). 
Los que se dedican a la comercialización y explotación de las flores son aproximadamente 150 países a nivel mundial, pero Japón y América del Norte son los que tienen más en producción, en cambio, la Unión Europea señala que por su antigüedad de sus mercados tradicionales y en volúmenes de producción son los que mayor consume. Por otro lado, aparecen nuevos productores que se encuentran en Latinoamérica y centro de África en donde está logrando ubicarse en el mercado (Ramírez \& Avitia, 2017).

La demanda de las flores el 74\% cubren los países de Holanda, Colombia y Ecuador, debido a que son los principales exportadores de flores a nivel internacional. Holanda es el principal en importaciones y exportaciones de flores, pero también es el mayor consumidor junto a los países de EE.UU. y Alemania (Morocho, Cisneros, \& Soto, 2021).

\section{PRODUCCIÓN DE ALGUNOS PRODUCTOS AGRÍCOLAS EN ECUADOR}

Ecuador es un país rico en producción agrícola de los productos de mayor importancia que se exportan están el banano y cacao que han sostenido durante años la economía. Del mismo modo, las flores, el atún y el café han logrado posicionarse en los mercados de Medio Oriente. Así también, el camarón ecuatoriano es considerado como uno de los mejores en todo el mundo.

En las exportaciones no petrolera del país entre enero-agosto de 2020 subió a USD 9.664 millones, quiere decir que, hubo un aumento del 8\% en relación del 2019 del mismo periodo. También con respecto al volumen de las exportaciones demostró que tuvo un incremento de $5 \%$ y los principales productos que se exportaron son: banano, camarón, enlatados de pescado y flores (Farías, y otros, 2020).

El banano llegó a un nivel más alto en el 2020 en cuanto a la producción en donde le permitió realizar sus envíos a más de diez países en los mercados de todo el mundo, la cual Europa y Rusia ocuparon los primeros destinos de exportación de esta fruta. Los países que compiten frente al banano ecuatoriano son: Colombia, Costa Rica y Filipinas.

Sin embargo, las exportaciones de banano en el 2020 mostraron un aumento del $7 \%$ en volumen y el 15\% en dólares, relacionado con el año anterior, acotó Marianela Ubilla, presidenta del directorio de la AEBE (Asociación de Exportadores de Banano del Ecuador). Esto fue gracias a que este sector consiguió un nuevo objetivo que era vender 380 millones de cajas de banano durante en ese periodo (Cámara Marítima del Ecuador, 2021). Por ello, el sector bananero representa el 2\% en el PIB general y cerca del $35 \%$ del PIB agrícola en las exportaciones del país.

José Hidalgo, Director Ejecutivo de AEBE acotó que gracias a la implementación de un clúster bananero se obtuvo una visión indispensable para unirse con los actores que están dentro de la cadena de valor de este producto. Así mismo, un enfoque hacia la competencia y sostenibilidad, ya sea ambiental 
como social, con la finalidad de generar más políticas públicas que ayuden en el crecimiento de divisas, así como también crear y desarrollar más fuentes de empleo para los trabajadores de zonas rurales (AEBE, 2020).

Con una tasa de variación positiva de 5,2\% en relación con el año anterior, presentó el sector camaronero motivo que, en el mercado externo hubo más demanda del producto, que mostró un aumento del 6,7\% toneladas métricas; es decir, en volúmenes exportados fueron mayores hacia EE.UU. donde subieron en un 47,1\% (Banco Central del Ecuador, 2021).

Las industrias del cultivo del camarón hacen frente a diversos desafíos como son las variedades de enfermedades fúngicas, bacterianas y víricas; así como también, en los ingredientes nuevos y agregados que se utilizará para elaborar y soportar un aumento de la demanda en los alimentos acuícolas, el impacto con el medio ambiente y finalmente en los temas y mercados de inversiones (Jaramillo, Argüello, \& Pacific Advisor, 2020).

Por lo tanto, se espera que la industria camaronera es uno de los sectores que ligeramente va salir frente a la pandemia, la cual este producto depende del consumo mundial, específicamente de economía más desarrolladas, de tal manera que, sumándole más divisas ayudará activar nuevamente la economía del país (Paladines, Moreno, \& Vásconez, 2020).

El cultivo de las flores en el país, hoy en día, forma parte de los sectores no petroleros más importantes debido a que, es uno de los productos que más se exporta hacia los mercados internacionales, considerándose como un mercado de producción estratégico para la economía ecuatoriana (Masabanda, Zambrano, Chiluisa, \& Jiménez, 2019).

Cabe señalar también que, el sector florícola es el primer productor y el tercer exportador mundial de rosas, cuyas características principales es la calidad y colores debido que son muy conocidas internacionalmente, la cual sus principales competidores son Colombia y Kenia, entre otros países de menor producción. Hasta el año pasado este sector se convirtió en el cuarto rubro de exportación de productos no petroleros después del banano, camarón, productos procesados y pescado fresco (Armijos, 2021).

Por ende, el sector florícola contribuye ampliamente al PIB y también se ha fortalecido en los mercados a nivel mundial cubriendo el $9,7 \%$ en la demanda de las flores. Por otro lado, aproximadamente se produce y exporta 450 diversidades de flores, es decir, más que el de sus competidores y distribuye en volumen de producción entre 8\% y 12\% (Sozoranga \& Vélez, 2016). 


\section{METODOLOGÍA}

Para llevar a cabo la realización del trabajo se desarrolló una investigación de tipo no experimental, por ende, los datos se demostrarán de manera única y originaria expresando toda la información de la situación actual.

Así mismo, se utilizó el método descriptivo, es aquel que ayuda a explicar la información existente y mirar las situaciones que lleven a nuevos hechos, por ello, nos permitirá identificar el impacto del covid19 de los sectores de banano, camarón y flores durante el 2020.

Para el trabajo se comenzó con la revisión bibliográfica con datos estadísticos y teóricos a partir de páginas oficiales como: Expoflores, CNA, BCE, FEDEXPORT, CFN, CEPAL entre otros, y posteriormente para la sección de resultados fueron realizadas en Excel y que se expondrá Tablas y Figuras con un análisis proporcional.

\section{RESULTADOS}

\subsection{EXPORTACIONES DE BANANO}

Para el 2020 las exportaciones de banano se situaron en 380 millones de cajas de enero-diciembre, el 6,58\% fue más de lo que se exportaron si relacionamos con el año anterior, para el mes de enero se exportó 37.6 millones de cajas, pero cuando llegó el virus al país, las exportaciones se fueron reduciendo, la cual para el mes de febrero 33.6 millones y marzo 33 millones de cajas de banano (ACORBANEC, 2021). Podemos observar en la Tabla 1:

Tabla 1: Progreso en cajas de las exportaciones de banano del Ecuador

\begin{tabular}{|ccc}
\hline Mes & $\mathbf{2 0 1 9}$ & $\mathbf{2 0 2 0}$ \\
\hline Enero & 31.769 .012 & 37.670 .960 \\
\hline Febrero & 29.598 .329 & 33.649 .615 \\
\hline Marzo & 33.907 .855 & 33.019 .699 \\
Abril & 32.358 .742 & 35.799 .490 \\
\hline Mayo & 30.694 .883 & 35.450 .941 \\
\hline Junio & 29.060 .296 & 28.377 .658 \\
\hline Julio & 25.688 .739 & 26.356 .694 \\
\hline Agosto & 27.265 .904 & 30.321 .514 \\
\hline Septiembre & 27.990 .986 & 26.338 .188 \\
\hline Octubre & 25.487 .081 & 28.122 .246 \\
\hline Noviembre & 30.725 .737 & 32.373 .667 \\
\hline Diciembre & 32.455 .835 & 33.012 .443 \\
\hline Total & $\mathbf{3 5 7 . 0 0 3 . 3 9 9}$ & $\mathbf{3 8 0 . 4 9 3 . 1 1 5}$ \\
\hline Variación & $\mathbf{6 . 4 4 1 . 2 3 1}$ & $\mathbf{6 3 . 4 8 9 . 7 1 6}$ \\
\hline \% Variación & $\mathbf{1 , 8 4 \%}$ & \\
\hline & Fuente: ACORBANEC (2021) &
\end{tabular}

En la Tabla 2 muestra los destinos que se exporta el banano ecuatoriano, relativamente refleja que los países de la Unión Europea (Alemania, Bélgica, Bulgaria, Chipre, Croacia, Dinamarca, España, 
Eslovenia, Finlandia, Francia, Grecia, Irlanda, Italia, Lituania, Malta, Países Bajos, Polonia, Portugal, Rumania, Suecia); Rusia; Medio Oriente(Arabia Saudita, Bahréin, Emiratos Árabes Unidos, Irán, Irak, Israel, Jordania, Kuwait, Omán, Qatar, Siria, Turquía); Cono Sur (Argentina, Chile, Uruguay); Europa Este ( Albania, Armenia, Azerbaiyán, Bielorrusia, Georgia, Kazajistán, Kirguistán, Moldavia, Montenegro, Tayikistán, Turkmenistán, Ucrania, Uzbekistán); África (Algeria, Egipto, Libia, Marruecos, Sudáfrica, Togo, Túnez, República Centroafricana); Reino Unido y EFTA (Noruega) tuvieron un incremento; mientras que, en Asia Oriental (China, Japón, Indonesia, Corea del Sur, Mongolia, Singapur), EE.UU. y Oceanía (Nueva Zelanda) obtuvieron una disminución.

Tabla 2: Exportaciones de banano del Ecuador por destinos en cajas

\begin{tabular}{ccccccc}
\hline Destinos & $\mathbf{2 0 1 9}$ & $\mathbf{\%}$ & $\mathbf{2 0 2 0}$ & $\mathbf{\%}$ & Variación & $\begin{array}{c}\text { \% Variación } \\
\mathbf{2 0 1 9 - 2 0 2 0}\end{array}$ \\
\hline Unión Europea & 92.058 .376 & $25,79 \%$ & 100.835 .237 & $26,50 \%$ & 8.776 .861 & $9,53 \%$ \\
Rusia & 75.542 .650 & $21,16 \%$ & 76.465 .173 & $20,10 \%$ & 922.523 & $1,22 \%$ \\
Medio Oriente & 53.054 .136 & $14,86 \%$ & 59.418 .610 & $15,62 \%$ & 6.364 .474 & $12 \%$ \\
EE.UU. & 37.095 .896 & $10,39 \%$ & 36.895 .832 & $9,70 \%$ & -200.064 & $-0,54 \%$ \\
Asia Oriental & 29.425 .384 & $8,24 \%$ & 26.676 .428 & $7,01 \%$ & -2.748 .956 & $-9,34 \%$ \\
Cono Sur & 23.368 .742 & $6,55 \%$ & 25.829 .756 & $6,79 \%$ & 2.461 .014 & $10,53 \%$ \\
Europa Este & 17.532 .846 & $4,91 \%$ & 21.287 .918 & $5,59 \%$ & 3.755 .072 & $21,42 \%$ \\
África & 16.874 .856 & $4,73 \%$ & 21.032 .833 & $5,53 \%$ & 4.157 .977 & $24,64 \%$ \\
Reino Unido & 6.516 .247 & $1,83 \%$ & 6.612 .449 & $1,74 \%$ & 96.202 & $1,48 \%$ \\
Oceanía & 3.768 .392 & $1,06 \%$ & 3.523 .154 & $0,93 \%$ & -245.238 & $-6,51 \%$ \\
\hline EFTA & 1.765 .874 & $0,49 \%$ & 1.915 .725 & $0,50 \%$ & 149.851 & $8,49 \%$ \\
\hline TOTAL & $\mathbf{3 5 7 . 0 0 3 . 3 9 9}$ & $\mathbf{1 0 0 \%}$ & $\mathbf{3 8 0 . 4 9 3 . 1 1 5}$ & $\mathbf{1 0 0 \%}$ & $\mathbf{2 3 . 4 8 9 . 7 1 6}$ & $\mathbf{6 , 5 8 \%}$ \\
\hline \multicolumn{7}{c}{ Fuente: ACORBANEC $(2021)$} \\
\end{tabular}

En la Figura 1 nos enseña el precio de la caja de banano al productor, para los meses de enero y febrero el precio fue superior; mientras que, en los meses de marzo a octubre disminuyeron los precio a causa del covid-19 y noviembre-diciembre se mantuvieron con el mismo precio.

Figura 1. Precio de la caja al productor bananero en el Ecuador

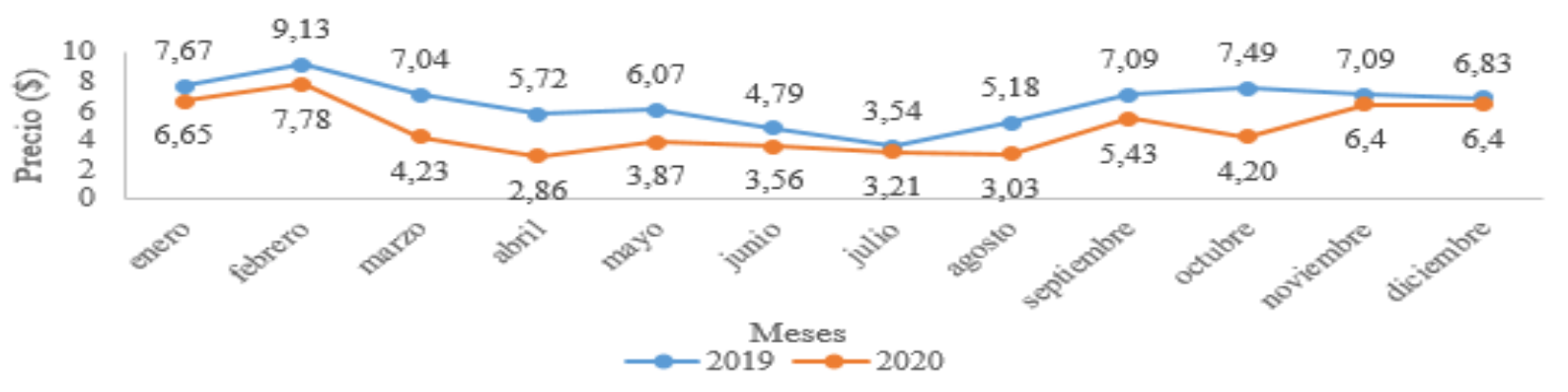

Fuente: Corporación Nacional Financiera (2020) 
El buen resultado obtenido durante la pandemia en las exportaciones del banano ecuatoriano fue:

1. Por el aumento de las inversiones que se realizaron en el año 2019 le permitió sostener mayor producción para el siguiente año, es decir, plantas de banano se sembraron cerca de 4.000 ha. y 4.000 más se resembraron, en donde se ha venido trabajando en la conformación de clúster bananero. Por otro lado, le ha permitido hasta la fecha reunir cerca del 100\% de las exportaciones, más el $50 \%$ en la producción local y en los diversos niveles de la cadena de valor, y

2. La industria ya estaba preparada con las medidas de bioseguridad desde años anteriores, debido a que este sector se enfrentaba con la Fusarium raza 4, un hongo que puede acabar con toda la fruta en producción (ACORBANEC, 2021).

A pesar de la situación mundial que se vive por la pandemia, el banano no solo se identifica como el más importante de los productos de exportación agrícola, al contrario, estuvo a punto de ubicarse como fuente esencial de divisas externas por arriba del petróleo (ACORBANEC, 2021).

\subsection{EXPORTACIONES DE CAMARÓN}

En el sector camaronero es, quizás, la primera vez que la industria se ve afectada por un virus que no ataca a la especie producida, sino a sus consumidores y en la economía en general. Sin embargo, la industria camaronera se recuperó rápidamente, gracias a las mejoras en producción y tecnología, posicionamiento del producto e independencia de la demanda local. Por otro lado, los productores presentaron problemas como situar sus pescas, proceso de comercialización, disminución de los precios y ausencia del personal. De manera que, también existen otros problemas como: los laboratorios de larvas que tienen dificultad de localizar sus producciones, demora en los pagos y poca materia prima hacia los proveedores de insumos y alimentos (Paladines, Moreno, \& Vásconez, 2020).

Este sector a inicios del 2020 tuvo una buena cantidad en exportaciones, pero a partir del mes de marzo las exportaciones del camarón disminuyó a causa por el covid-19; en donde la Tabla 3 nos proporciona datos en libras y dólares de los años 2019 y 2020, la cual para el 2020 tuvo una variación de porcentaje anual en libras del $7 \%$ y dólares $-1 \%$.

Tabla 3: Exportaciones de camarón del Ecuador en libra-dólares

\begin{tabular}{|c|c|c|c|c|c|}
\hline & & & & Libras & Dólares \\
\hline Periodo & Libras & & Dólares & \multicolumn{2}{|c|}{ \% Variación } \\
\hline ene-dic 2017 & 938.583 .529 & $\$$ & 2.860 .631 .433 & - & - \\
\hline ene-dic 2018 & 1.115 .223 .755 & $\$$ & 3.198 .715 .523 & $19 \%$ & $12 \%$ \\
\hline ene-dic 2019 & 1.397 .490 .379 & $\$$ & 3.652 .684 .081 & $25 \%$ & $14 \%$ \\
\hline ene-dic 2020 & 1.491 .132 .214 & $\$$ & 3.611 .870 .630 & $7 \%$ & $-1 \%$ \\
\hline
\end{tabular}


Las exportaciones de camarón en el 2020, se puede observar en la Figura 2 que en el mes de julio hubo una contracción debido a que, la Administración General de Aduana (GACC) de China comunicó al gobierno ecuatoriano que encontró rastros de covid-19 en la superficie de empaques y una pared interior de un contenedor de las tres empresas que exportan camarón hacia ese país, por ello, china suspendió la compra de camarón ecuatoriano, debido que, en el mercado interno hubo una gran cantidad del producto lo que causó el desplome de precio, donde se cotizó en los mercados internacionales como el más económico. No obstante, fue otra caída para este sector, motivo por el que China representa el 65\% de las exportaciones ecuatorianas (Poveda \& Piedrahita, 2020)

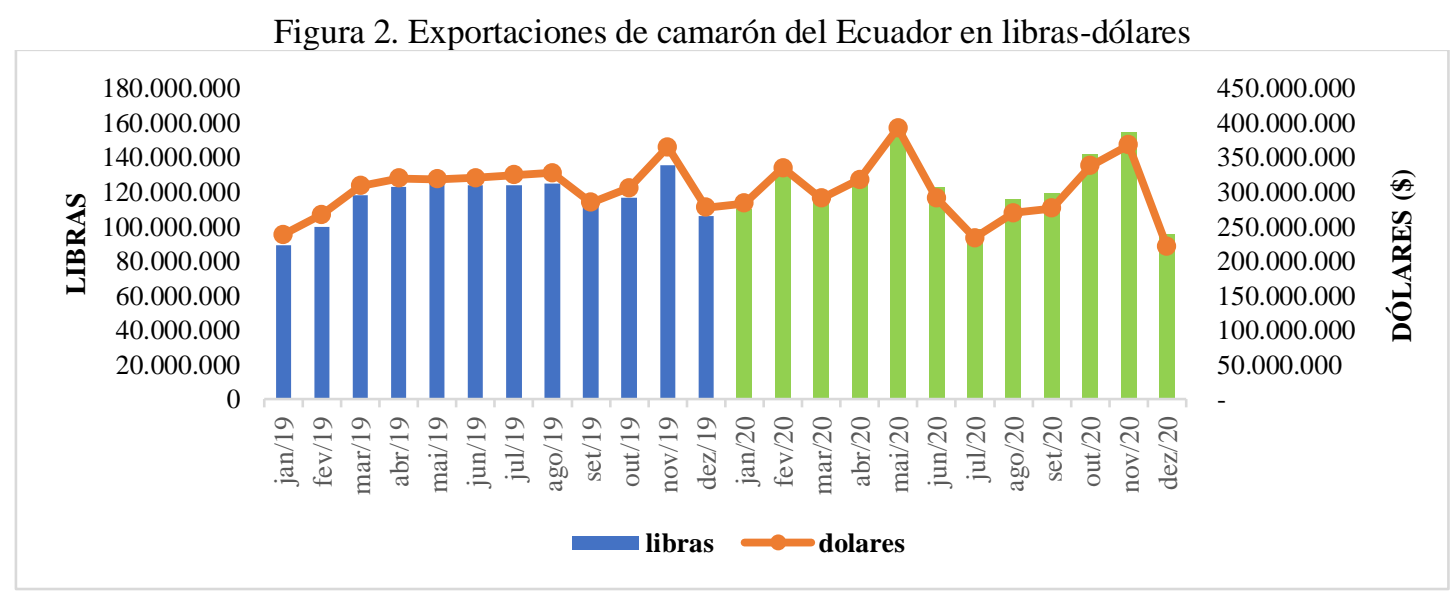

Fuente: Cámara Nacional Acuicultura (2020)

Para el 2020 el precio promedio anual del camarón es USD 2,42 si comparamos con el 2019 fue de USD 2,63 (Cámara Nacional de Acuacultura, 2020) de tal manera miramos en la Figura 3:

Figura 3. Evolución de precio promedio/libra del camarón ecuatoriano

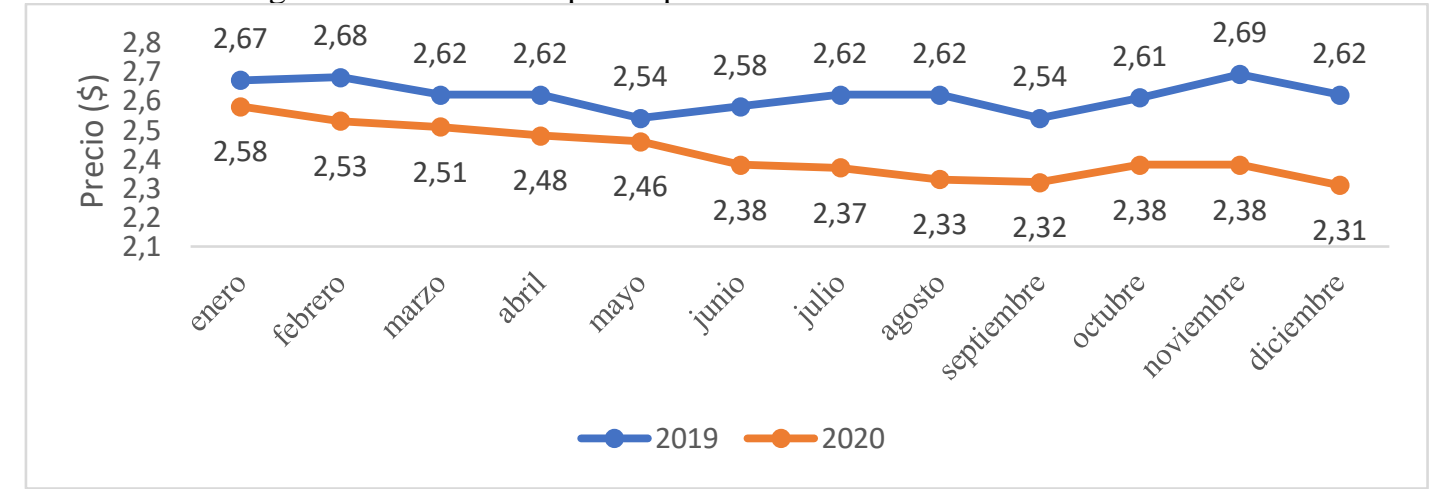

Fuente: Cámara Nacional de Acuacultura (2020)

A pesar de la situación de la pandemia en este sector, después de los desplomes de los precios los exportadores tuvieron que buscar otros destinos para poder ubicar el producto, de forma que EE.UU. continuado de los países europeos, se envió el producto antes que cerraran sus puertos y entren a 
confinamiento ante la llegada de la pandemia. Por ende, gracias a estos dos grandes mercados han brindado un resultado favorable con referente al consumo y las compras del producto ecuatoriano subieron (Poveda \& Piedrahita, 2020)

En los siguientes datos de la Figura 4 nos indica cómo fue la variabilidad de la participación del mercado (\%) de los países que se exporta el camarón ecuatoriano para los años 2019-2020, la cual en Asia disminuyó, EE.UU., Europa, en el resto de países de América hubo un aumento y África se ha mantenido.

Figura 4. Destinos de exportación del camarón ecuatoriano

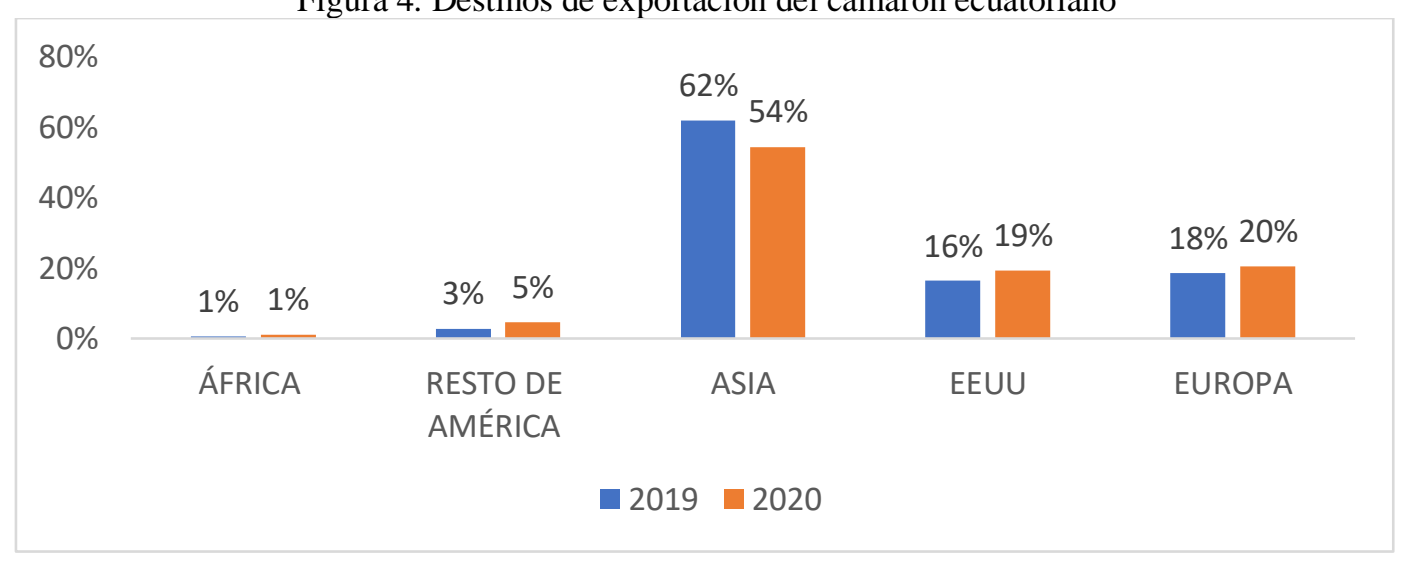

Fuente: Cámara Nacional de Acuacultura (2020)

José Camposano, presidente de la CNA menciona que no se ha ocasionado una crisis en el sector acuícola, parecida al año de 1999, que fue por la presencia del virus de la mancha blanca mismo que perjudicó a las piscinas camaroneras.

\subsection{EXPORTACIONES DE LAS FLORES}

El sector florícola cuenta con 4.900 hectáreas cultivadas, con más 1.700 fincas productoras, más de 600 empresas exportadoras, con más 100 destinos de exportación, por ende, este sector representa el 10\% del PIB agrícola y con una generación de divisas de USD 827 millones de dólares (Expoflores, 2021) En la Tabla 4 podemos observar cómo fue la situación del sector florícola si comparamos con el 2019:

Tabla 4: Cuadro comparativo 2019-2020 del sector florícola del Ecuador

\begin{tabular}{|c|c|c|c|}
\hline Rubros & 2019 & 2020 & $\begin{array}{c}\text { Variación } 2019- \\
2020\end{array}$ \\
\hline USD millones & 880 & 827 & $-6,02 \%$ \\
\hline Miles de toneladas & 158 & 153 & $-3,16 \%$ \\
\hline USD por kilo & 5,6 & 5,4 & $-3,57 \%$ \\
\hline Número de destino & 130 & 110 & -20 \\
\hline Superficies cultivadas & 5700 & 4900 & $-14,04 \%$ \\
\hline Participación en exportaciones no petroleras & $6,40 \%$ & $5,50 \%$ & \\
\hline
\end{tabular}

Fuente: Expoflores (2021) 
Los principales destinos de exportación del sector florícola, como podemos observar en la Figura 5 tenemos: la Unión Europa, EEUU, China, Rusia y Colombia. Entonces el país que tuvo mayor participación en las exportaciones de las flores es Rusia que tiene el 12\%, mientras que, China es el de menor participación $0,3 \%$. Por otro lado, en ventas de este sector el país que más compró fue la Unión Europea de USD 3.314 millones durante el 2020.

Figura 5. Destinos de exportaciones de las flores del Ecuador en el 2020

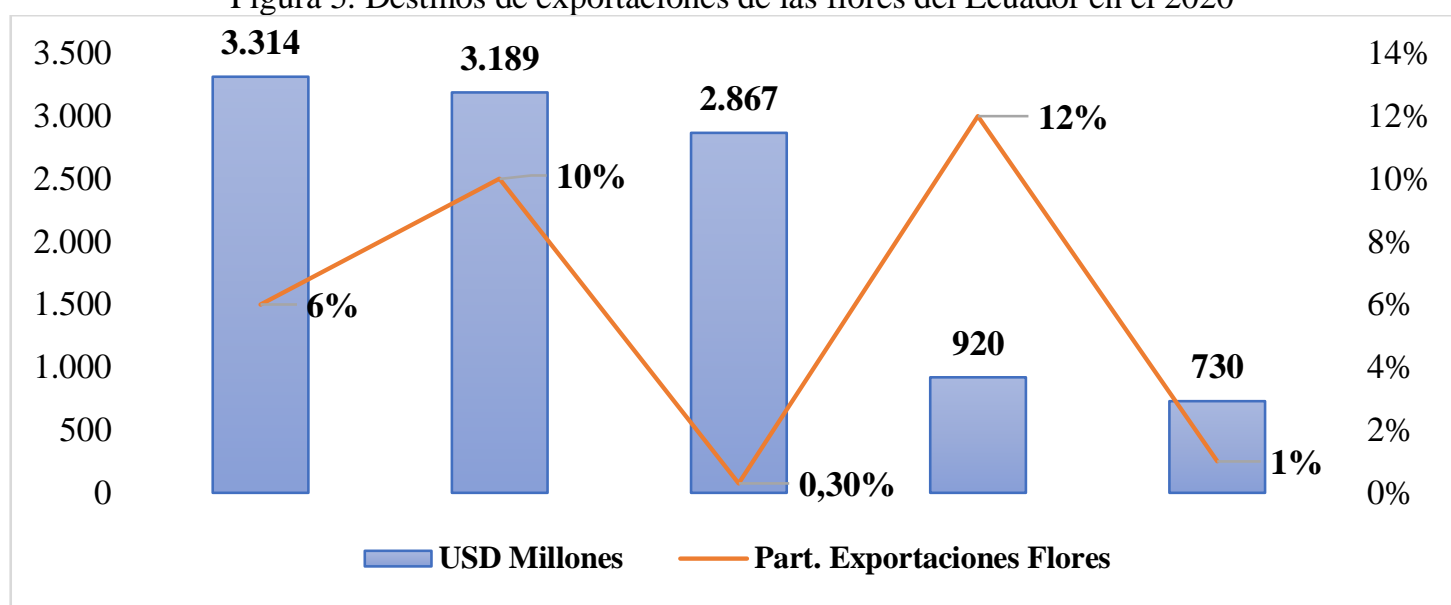

Fuente: Expoflores (2021)

En la Figura 6 enseña el precio de las exportaciones del sector florícola durante la pandemia, en donde ha sostenido un movimiento más activo, pero hubo meses con fuertes descenso; la cual esto afectó en el precio que disminuyó en un 3\% en el 2020 Por ello, obtenemos como resultado un valor menor del $6 \%$ en las exportaciones de las flores en relación del año anterior.

Figura 6. Tendencia de precios de las flores del Ecuador en el 2020

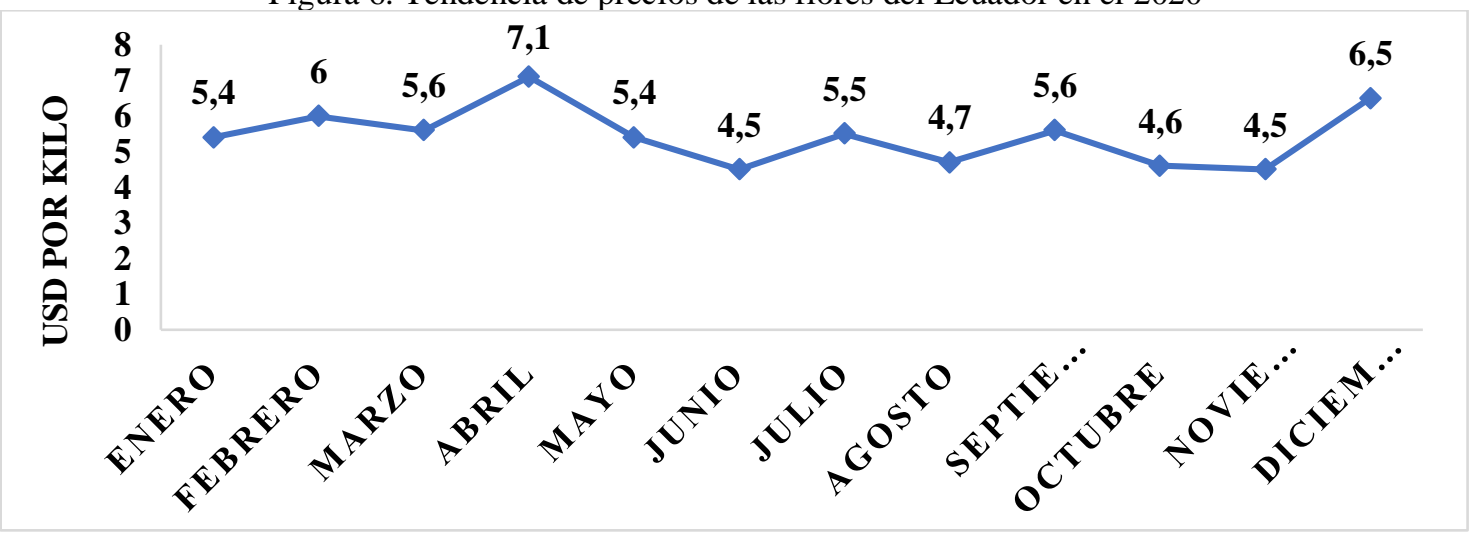

Fuente: Expoflores (2020)

Según Expoflores, en el sector florícola se calcula que crea aproximadamente 100.000 empleos de manera directa e indirecta especialmente para mujeres. Entre febrero y mayo son los meses de mayor demanda por motivo a las festividades de San Valentín y Día de la Madre. Para ello, en el mes de febrero 
del presente año se exportaron 1.000 toneladas más en relación del 2019, a pesar de que las toneladas en ventas incrementaron, debido a que, no perfila un buen ingreso económico para los productores en donde han demostrado que disminuyó los precios de las flores debido a que los niveles de sobre producción y las cosechas se adelantaron por motivos del cambio climático (Alvarez, Vera, \& Soto, 2021).

En estos últimos seis meses este sector de las flores ha estado atravesando situaciones difíciles que fueron causados por un paro nacional en octubre del 2019 y a comienzos del 2020 la propagación del nuevo virus en aquellos países que son compradores de flores alrededor del mundo.

Las graves afectaciones que tuvo este sector durante la pandemia fueron las cancelaciones de pedidos de sus clientes y cerca del total de la producción hubo que desecharla. Por otro lado, en temas de logísticas en el transporte internacional aumentaron los precios y hubo escasez de cupos de aerolíneas (Farías, y otros, 2020).

\section{DISCUSIÓN}

La producción de banano para el mes de abril el precio de la caja fue de USD 2,50 es decir, fue USD 3,50 menor a lo que se ofreció para el mes de enero. Sin embargo, hace referencia solo al precio del banano entregado fuera de contrato, donde los productores están aliados con los importadores que tienen un valor de USD 6,40 la caja. Cerca del 60\% de los exportadores trabajan con contratos negociados con anterioridad, esto coincidiendo con lo planteado por Chóez et al., (2020) en su trabajo sobre exportaciones ecuatorianas un análisis a la producción no afectada por la emergencia sanitaria.

Los problemas comerciales y logísticos que se presentaron en el sector bananero permanecieron estables. En cuanto a producción del banano creció en un 3,6\% en el último trimestre del 2020, además se convirtió en el primer proveedor de banano hacia Europa, por ello, se esperaba que para el primer trimestre del 2021 haya un crecimiento del 2 y 3\% en volúmenes de exportación, coincidiendo con algunos trabajos realizados, según Armas et al., (2018); Chóez et al., (2020) y Bravo (2021) que realizan un análisis de la concentración del mercado del sector agrícola en el Ecuador.

Este desplome del precio fue afectado, porque China prohíbe el consumo, la compra, venta y utilización del camarón ecuatoriano en varios estados chinos debido a que encontró rastros de covid-19 de las tres empresas que exportan hacia ese mercado. Por esta razón, la demanda a nivel internacional decreció, así como también en contenidos de logística y transporte interno presentaron problemas. Sin embargo, pasó ser el principal producto no petrolero en exportación en el 2020, la cual tuvieron ingresos de USD 3.580 millones con 637 mil toneladas métricas, coincidiendo con lo planteado Alvarez, Vera \& Soto (2021) en su trabajo investigativo sobre el impacto económico en las exportaciones del sector camaronero ecuatoriano en el periodo 2019-2020 
El sector florícola ha sido uno de los sectores más perjudicados, en donde hubo un decrecimiento del coste por variedad de las flores, aumento en el coste de envío y en el costo de producción; es decir, la mano de obra de forma directa e indirecta que se utilizan en el segmento de producción provocando pérdidas para las empresas florícolas, los trabajos desarrollados por Mackay et al., (2020) y Bravo (2021) establecen resultados similares en que la demanda de las flores decreció, por el desplome de la economía de los mercados importantes como China, EE.UU. y Europa.

Algunos trabajos recientes Farías et al., (2020); Tapia (2020); Mackay et al., (2020) y Bravo (2021) establecen que para los meses de marzo y junio de 2020 se perdieron USD 130 millones en los primeros meses de la pandemia. Así mismo el empleo de manera directa fue 10.000 e indirectas 6.000, con un total de 16.000 plazas se perdieron, debido a esta situación provocó una disminución del 17\% en plantaciones; es decir, 800 y 900 hectáreas. En este sentido el trabajo basado en analizar el impacto del covid-19 en las exportaciones de banano, camarón y flores tomando en cuenta los factores preponderantes que han hecho que este sector se vea afectado tanto de manera positiva como negativa durante el periodo 2020 responde a la necesidad planteada desde el análisis de la demanda.

\section{CONCLUSIONES}

El impacto que tuvieron las exportaciones ecuatorianas fue positiva durante el 2020, donde los productos que más resaltaron fueron el banano y camarón durante la pandemia, sus principales mercados fueron EE.UU., China y la Unión Europea.

Las exportaciones de banano aumentaron en 6,58\% durante el 2020, se exportó más cajas en comparación al año anterior. Esto fue gracias a que se ha venido realizando inversiones desde años anteriores para implementar un nuevo clúster bananero y que en sus exportaciones se mantuvo estable.

El camarón ecuatoriano es considerado como el mejor a nivel internacional, la cual en volumen tuvo un aumento del $7 \%$ y en el ingreso de divisas obtuvo una disminución 1\%. Para el mes de julio del 2020 sus exportaciones disminuyeron debido que China encontró rastros de covid-19 en el producto de las tres empresas camaroneras que se exportan, y después de algunos meses se realizaron los estudios en los contenedores y finalmente los resultados que se obtuvieron fueron negativos a la presencia del virus y con eso ayudó que China pueda volver a comprar el camarón ecuatoriano y se sigan exportando.

Las flores ecuatorianas son muy reconocidas alrededor del mundo, ya sea por su color, variedad, calidad entre otras características. En términos de millones de dólares, las exportaciones de las flores disminuyeron en un $6 \%$, debido a que, se exportaron menos toneladas y que el precio bajó a causa de la pandemia, provocando la suspensión de pedidos por los clientes y la mayor parte de su producción fue desechada. 


\section{REFERENCIAS BIBLIOGRÁFICAS}

ACORBANEC. (10 de enero de 2021). Analisis de las exportaciones de banano del ecuador: de enero a diciembre del 2020. Obtenido de http://www.acorbanec.com/wp-content/uploads/2021/01/10-evolucionde-exportaciones-ecuatorianas-de-banano-a-diciembre-de-2020.pdf

AEBE. (noviembre-diciembre de 2020). Revista Bananotas. Obtenido de nuestro banano principal producto de exportación durante la pandemia: https://fb329f0a-8a6c-4216-9e2fdcf8067bce4d.filesusr.com/ugd/f4cd67_61e6a9a49a7d43a9bab8af1700afea14.pdf?index=true

Armas, J. A. A., Mena, S. F. B., Vera, K. T., \& Herrera, M. E. C. (2018). Modelo de comercialización de productos generadores del valor agregado en base al banano. Dilemas contemporáneos: Educación, Política https://www.dilemascontemporaneoseducacionpoliticayvalores.com/index.php/dilemas/article/view/910

Alvarez, M., Vera, K., \& Soto, C. (2021). Covid-19: Impacto económico en las exportaciones del sector camaronero ecuatoriano en el periodo 2019-2020. 593 Digital Publisher, 6(3), 133-145. Obtenido de https://www.593dp.com/index.php/593_Digital_Publisher/article/view/551/674

Bravo, M. A. (2021). Análisis de la concentración del mercado del sector agrícola en el Ecuador. Período 2015 - 2019. In Cumbres (Vol. 7, Issue 1, pp. 55-66). https://doi.org/10.48190/cumbres.v7n1a5

BCE. (31 de marzo de 2021). La pandemia incidió en el crecimiento 2020: la economía ecuatoriana decreció 7,8\%. Obtenido de https://www.bce.fin.ec/index.php/boletines-de-prensa-archivo/item/1421-lapandemia-incidio-en-el-crecimiento-2020-la-economia-ecuatoriana-decrecio-7-8

Beltrán, M. (2017). innovación en el sector acuícola. Revista Ra Ximhai, 13(3), 1-15. Obtenido de https://www.redalyc.org/pdf/461/46154070020.pdf

CAMAE. (21 de enero de 2021). Exportación bananera alcanza nuevo récord al comercializar 380 millones de cajas en el 2020. Obtenido de http://www.camae.org/exportaciones/exportacion-bananeraalcanza-nuevo-record-al-comercializar-380-millones-de-cajas-en-el-2020/

Cámara Nacional de Acuacultura. (2020). Camarón - Reporte de Exportaciones Ecuatorianas Totales. Obtenido de https://www.cna-ecuador.com/estadisticas/

CEPAL. (2020). Los efectos del COVID-19 en el comercio internacional y la logística. Informe Especial Covid-19. Obtenido de https://repositorio.cepal.org/bitstream/handle/11362/45877/1/S2000497_es.pdf

Corporación Nacional Financiera. (2020). Ficha sectorial. Obtenido de Banano y Plátano: https://www.cfn.fin.ec/wp-content/uploads/downloads/biblioteca/2020/ficha-sectorial-4-trimestre2020/FS-Banano-4T2020.pdf

Expoflores. (2021). Reporte Estadístico Anual 2020. Obtenido de https://expoflores.com/wpcontent/uploads/2021/03/Anual-Expoflores.pdf

FAO. (2020). Análisis del mercado del banano . Obtenido de Panorama general de febrero de 2020: http://www.fao.org/3/ca9212es/ca9212es.pdf 
Farías, R., Muñoz, L., Marcillo, C., Viteri, M., Vinueza, J., Galarza, C., \& Cevallos, J. (2020). Ministerio de Producción, Comercio Exterior, Inversiones y Pesca; PROECUADOR; UTE; ESPE. Obtenido de COVID-19: impacto en las exportaciones de organizaciones de pequeños productores afectaciones, desafíos y oportunidades: https://www.produccion.gob.ec/wp-content/uploads/2020/12/Doc-completoImpacto-Exportaciones-EPS.pdf

Jaramillo, E., Argüello, A., \& Pacific Advisor. (10 de julio de 2020). Revista Ekos. Obtenido de El camarón le da batalla a la pandemia: https://www.ekosnegocios.com/articulo/el-camaron-le-da-batalla-ala-pandemia

La Hora. (29 de septiembre de 2020). Banano casi supera al petróleo como principal producto de exportación larante la pandemia. Obtenido de https://lahora.com.ec/esmeraldas/noticia/1102328874/banano-casi-supera-al-petroleo-como-principalproducto-de-exportacion-durante-la-pandemia

Lucero, K. (8 de noviembre de 2020). Revista Gestión. Obtenido de Los productos tradicionales siguen sosteniendo al comercio exterior del país: https://www.revistagestion.ec/economia-y-finanzasanalisis/los-productos-tradicionales-siguen-sosteniendo-al-comercio-exterior

Mackay, C., Franco, Z., Ruíz , K., González, G., \& Poveda, G. (2020). Congreso internacional virtual sobre covid-19. Consecuencias psicológicas, sociales, políticas y económicas. Obtenido de el sector florícola ecuatoriano y su afectación en el mercado internacional producto de la pandemia causada por el covid-19: https://www.eumed.net/actas/20/covid/5-el-sector-floricola-ecuatoriano-y-su-afectacion-en-elmercado-internacional.pdf

Masabanda, G., Zambrano, A., Chiluisa, K., \& Jiménez, O. (2019). Enfermedades ocupacionales derivadas de agentes químicos a los que se exponen trabajadores del sector floricultor de la ciudad de Latacunga, Ecuador. Revista Gaceta Laboral, 25(3), 155-170. Obtenido de https://produccioncientificaluz.org/index.php/gaceta/article/view/32980/34585

Morocho, N., Cisneros, M., \& Soto, C. (2021). EL COVID 19 y su impacto financiero en el sector florícola ecuatoriano. Análisis comparativo. 593 Digital Publisher, 6(3), 146-157. Obtenido de https://www.593dp.com/index.php/593_Digital_Publisher/article/view/553/675

OMS. (27 de abril de 2020). COVID-19: cronología de la actuación de la OMS. Obtenido de https://www.who.int/es/news/item/27-04-2020-who-timeline---covid-19

Poveda, D., \& Piedrahita, Y. (22 de octubre de 2020). Global Aquaculture Alliance. Obtenido de La Industria Camaronera de Ecuador superando Numerosos Obstáculos en el 2020: https://aquafeed.co/entrada/la-industria-camaronera-de-ecuador-superando-numerosos-obstaculos-en-el2020-23709

Bravo. (2020). El efecto del covid-19 en la industria camaronera de Ecuador. Obtenido de https://www.procampo.com.ec/index.php/blog/10-nutricion/156-el-efecto-del-covid-19-en-la-industriacamaronera-de-ecuador

Ramírez, J., \& Avitia, J. (2017). Floricultura mexicana en el siglo xxi: su desempeño en los mercados internacionales. Revista de economía, 34(88), 99-122. Obtenido de http://www.scielo.org.mx/pdf/remy/v34n88/2395-8715-remy-34-88-99.pdf 
Sozoranga, H., \& Vélez, M. (10 de octubre de 2016). Revista Caribeña de Ciencias Sociales. Obtenido de la floricultura en el Ecuador: https://www.eumed.net/rev/caribe/2016/10/floricultura.html

Tapia, E. (13 de marzo de 2020). El Comercio. Obtenido de Sector florícola reporta $60 \%$ de caída en sus ventas por efectos del coronavirus: https://www.elcomercio.com/actualidad/floricola-expoflorescoronavirus-economia-flores.html 